\title{
O PAPEL DA CERTIFICAÇÃO NA PROTEÇÃO AMBIENTAL REALIZADA PELA ATIVIDADE AGRÁRIA*
}

THE ROLE OF CERTIFICATION IN ENVIRONMENTAL PROTECTION IMPLEMENTED

BY AGRARIAN ACTIVITY

\author{
Carolina Costa de Aguiar** \\ Flavia Trentini ${ }^{* * *}$
}

\begin{abstract}
Resumo
O presente trabalho busca demonstrar como a certificação da atividade agrária contribui para a implementação dos princípios ambientais e concretização da defesa do meio ambiente, fomentando as ações privadas convergentes com o interesse social de proteção ecológica. A partir disso, são elaboradas propostas de políticas públicas de incentivo à certificação, decorrentes da função do Estado de direcionar e promover a concretização da proteção ambiental, reconhecendo-se os benefícios sociais produzidos a partir da conduta privada e proporcionando ao agente condições para que continue a ser praticada. Dessa forma, espera-se que, uma vez implementada com eficientes regulamentações estatais e incentivos que levem à adoção pelos agentes econômicos, a certificação proverá maiores ganhos ambientais, a partir da maior concretização da proteção ambiental; menores custos para o Estado com fiscalização, processamento e sanção; e, a partir desses dois fatores, também menores custos sociais; além de promover a prática de uma atividade agrária que se coaduna com o ideal de um desenvolvimento sustentável.
\end{abstract}

Palavras-chave: Certificação. Externalidades positivas. Assimetria de informação.

\begin{abstract}
This paper aims to demonstrate how the certification of agrarian activity contributes to the implementation of environmental principles and environmental protection, encouraging private actions converged with the social interest of ecological protection. From this, the paper develops proposals of public policies to encourage certification, in accordance with the function of the state to direct and promote the implementation of environmental protection, recognizing the social benefits produced from the private conduct and providing the conditions to continue to be practiced. Thus, once implemented with efficient state regulations and incentives for the adoption of the certification by economic agents, it is expected that certification will provide environmental gains with a greater environmental protection, lower costs for the state with monitoring, processing and sanction, and in this way also lower social

\footnotetext{
* Pesquisa elaborada com fomento da Fundação de Amparo à Pesquisa do Estado de São Paulo (FAPESP) e premiado com uma Menção Honrosa no $3^{\circ}$ Prêmio Agroambiental Monsanto - Troféu Ernesto Paterniani.

Professora Doutora da Universidade de São Paulo. Faculdade de Direito de Ribeirão Preto. Doutora em Direito pela Universidade de São Paulo. Pós-Doutora em Administração/Economia das Organizações (FEA/USP). Tem experiência na área de Direito Privado, com ênfase em Direito Agroambiental e Direito do Consumidor. Atua também nos seguintes temas: desenvolvimento rural sustentável, biocombustíveis e propriedade industrial.

Mestranda em Direito pela Faculdade de Direito de Ribeirão Preto da Universidade de São Paulo e bacharela em Direito pela mesma instituição. Já atuou em projetos de pesquisa e extensão em temas de Direito Agrário, Direito Ambiental e Violência contra Mulher. Auxiliou em atividades docentes e coordenação de rede de pesquisa. Atualmente participa do Projeto "Energy Scarcity, Food Supply Chain Transformation, and Poverty Reduction in the Emerging Economies: the Case of Brazil, China and India", desenvolvido pelo International Food Policy Research Institute e Universidade de São Paulo.
} 
costs, as well as promoting the practice of an agrarian activity which is consistent with the ideal of sustainable development.

Keywords: Certification. Positive externalities. Information asymmetry.

\section{Introdução}

Meio ambiente é o espaço onde se encontram os recursos naturais, inclusive aqueles já transformados ou degenerados (DERANI, 2008, p. 52). Não obstante, conforme acrescenta Cristiane Derani, esse conceito não pode ser reduzido aos elementos tais como ar, água e terra, e sim deve ser considerado inclusive como o "conjunto das condições de existência humana, que integra e influencia o relacionamento entre os homens, sua saúde e seu desenvolvimento".

Desse modo, a proteção ambiental apresenta uma dupla dimensão: a defesa do meio ambiente como bem autônomo e como pressuposto da vida humana (LEITE; PILATI; JAMUNDÁ, 2005, p. 618). Este último aspecto, antropológico, refere-se à necessidade de um patamar mínimo de qualidade ambiental para o exercício da vida humana em níveis dignos, pois o equilíbrio ecológico constitui pré-requisito do gozo dos direitos fundamentais mais essenciais, como os direitos à vida e à saúde (CARVALHO, E., 2010, p. 448; SARLET, FENSTERSEIFER, 2011, p. 90) ${ }^{1}$.

É preciso considerar também que a concretização de uma qualidade de vida satisfatória está intrinsecamente relacionada à forma como a sociedade apreende e transforma seus recursos, ou seja, como desenvolve sua atividade econômica (DERANI, 2008, p. 224). O homem não é elemento externo ao meio ambiente, está nele compreendido como parte de um conjunto de relações econômicas, sociais e políticas construídas a partir da apropriação dos bens naturais, que se transformam em recursos essenciais para a vida humana em quaisquer de seus aspectos (ANTUNES, 2010, p. 9).

Todavia, com o crescimento da população mundial e desenvolvimento da produção e do consumo, a pressão sobre a natureza aumentou muito além de sua capacidade de resiliência, seja pelo uso cada vez mais intenso dos recursos naturais, seja pela quantidade de resíduos nela descartados. 
Dadas as atuais proporções do desastre ambiental e as consequências que já afligem tanto o meio natural quanto o homem, é preciso frear tamanha degradação e, para isso, torna-se imprescindível compatibilizar desenvolvimento econômico com a proteção ambiental, utilizando-se racionalmente os recursos naturais.

Se a atividade produtiva não se adequar a esses limites, além de comprometer o meio ambiente como bem autônomo e a sobrevivência digna das atuais e futuras gerações, ela mesma terá que cessar, pela falta dos recursos que lhe são necessários e fornecidos pela natureza.

Em razão disso, o Direito busca organizar a maneira pela qual a sociedade se utiliza dos recursos naturais (ANTUNES, 2010, p. 3), estabelecendo limites à atividade predatória do ser humano. Não com o intuito de impedir o crescimento econômico, mas apenas com o objetivo de balizar o modo como ele deve ocorrer, indicando que o desenvolvimento sustentável é a diretriz a guiar as atividades humanas, inclusive as econômicas ${ }^{2}$.

Ingo Sarlet e Tiago Fensterseifer (2011, p. 125) afirmam que a Constituição Federal de 1988 optou por um capitalismo socioambiental (ou economia socioambiental de mercado), voltada a compatibilizar, sob a perspectiva do desenvolvimento sustentável, a livre iniciativa, a autonomia privada e a propriedade privada com a proteção ambiental e a justiça social, como se pode depreender dos princípios que regem a ordem econômica ${ }^{3}$.

A Constituição estabelece um poder-dever em relação ao meio ambiente. Confere a todos o direito fundamental ao meio ambiente ecologicamente equilibrado e, simultaneamente, impõe ao poder público e à coletividade o dever de defendê-lo (BRASIL, 1988, art. 225). Há o compartilhamento de responsabilidades e obrigações que cabem não só ao Estado, mas também aos particulares, pessoas físicas ou jurídicas ${ }^{4}$.

Compete a todos a defesa do meio ambiente, entretanto, na prática são necessários incentivos às condutas privadas de proteção ambiental para que aquela deixe de ser uma norma abstrata e se concretize, sobretudo no tocante às atividades econômicas. A proteção ambiental não é o objetivo principal da empresa, o que torna necessária alguma pressão para que ela mude seu comportamento. 
Ao responder à pressão (do mercado, dos consumidores, dos stakeholders etc) quanto à proteção do meio ambiente, o agente busca o fazer de modo com que as boas condutas ambientais praticadas possam lhe agregar valor. Para isso, adota estratégias relacionadas à sua reputação e fidelização de clientes, acesso a mercados com demandas específicas e certificação ambiental, por exemplo.

Com isso, a empresa atende ao interesse social de proteção do meio ambiente e também ao seu objetivo de lucro, o que se torna um estímulo para que continue a agir dessa forma. Assim, é relevante analisar mecanismos que promovam essas condutas particulares benéficas ao meio ambiente, que podem ser muito eficientes para a tentativa de se compatibilizar desenvolvimento econômico e sustentabilidade ambiental.

O trabalho se propõe a investigar como a certificação de produtos derivados da atividade agrária, em especial, contribui para a proteção ecológica. A partir disso, busca analisar também qual a importância do Estado quanto aos incentivos à utilização desse instrumento, a fim de garantir a efetividade da defesa do meio ambiente.

\section{Externalidades Positivas da Atividade Agrária}

As externalidades, ou efeitos externos ao mercado, consistem nos efeitos sociais secundários da produção ou do consumo, que podem tanto ser positivos (representando ganhos para os terceiros), como negativos (implicando perdas para os terceiros). Em qualquer das situações, está presente a característica comum de não serem espontaneamente consideradas: quem causa obstáculos a outrem não os paga, quem cria benefícios a outrem não é compensado (ARAGÃO, 1997, p. 32).

As externalidades positivas produzidas pela empresa agrária estão ligadas ao conceito de multifuncionalidade da agricultura, pelo qual a atividade agrária desempenha outras funções além da produção de bens agrícolas e agroalimentares. O conceito compreende questões não-comerciais, relacionadas às ideias de preservação ambiental e de paisagens, bem-estar dos animais, estímulo ao emprego rural, manutenção cultural e desenvolvimento sustentável (WATANABE, 2008, p. 2). 
Trata-se da noção de um espaço rural multifuncional, com função econômica, ecológica e sócio-cultural, que não deve ser entendido somente como simples gerador de desenvolvimento econômico, mas sim abrangendo outros aspectos, relacionados, sobretudo, à necessidade de que o desenvolvimento seja um processo controlado, atento ao equilíbrio social e biológico (TRENTINI, 2012, p. 45).

O espaço rural multifuncional presta serviços ambientais cuja quase totalidade é indispensável à preservação de um ecossistema e, em última análise, à própria qualidade de vida do homem, não podendo ser providos por meios alternativos caso não exista a manutenção e proteção das fontes geradoras. Dessa forma, os benefícios são positivos e, também, essenciais, fazendo com que interesse à sociedade que continuem a ser produzidos ${ }^{5}$.

Percebe-se, então, que é possível e necessário que a atividade agrária promova o desenvolvimento econômico em consonância com o equilíbrio biológico. Como pondera Flavia Trentini (2012, p. 45), o desenvolvimento sustentável deve disciplinar todas as atividades produtivas e de modo particular a agrária, a qual necessita da utilização de muitos recursos naturais para a sua prática.

Deve-se considerar que a geração das externalidades positivas ambientais interessa à coletividade como um todo, mas representa também custos para aquele que as produz, que podem fazer com que a proteção deixe de ser realizada em níveis satisfatórios ao interesse social.

Ana Nusdeo (2006, p. 359) se refere às externalidades positivas como benefícios circulando extramercado ${ }^{6}$. A partir disso, a autora chama atenção para o fato de que a própria conceituação do termo externalidade deixa claro que se trata de um tema interdisciplinar localizado na fronteira de disciplinas como a economia, a ecologia e o direito, passando pela gestão de políticas públicas.

Considerando-se, assim, que o problema não se restringe ao campo do direito, possíveis soluções devem ser estudadas a partir da natureza (complexa) da questão que se apresenta. Por isso, junto ao aspecto jurídico, é preciso analisar as implicações econômicas das externalidades positivas. 


\subsection{Assimetria de informação e custos de transação}

Para realizar ações que colaboram positivamente para a proteção ambiental, o agente econômico incorre em variados custos, desde o custo direto para implementá-las, até custos indiretos porque essas ações podem limitar de alguma forma o desempenho de sua atividade econômica (por exemplo, a manutenção de espaços protegidos dentro da propriedade, os quais não poderão ser utilizados para a produção agrícola).

Além disso, surgem custos derivados de uma assimetria de informação, pois o mercado não consegue transportar naturalmente as informações necessárias para a percepção das externalidades positivas por outros agentes econômicos e consumidores (DERANI, 2008, p. 91).

Ou seja, a informação de que o processo produtivo ocorreu associado à proteção ambiental, que gerou despesas ao proprietário - as quais poderiam justificar o pagamento de um valor superior pelo bem ou serviço, que englobasse o ganho social - não são transmitidas pelo mercado. Consequentemente, surgirão custos de transação para eliminar tal assimetria, pois obter (ou fazer com que alguém obtenha) informação implica custos.

De acordo com Ronald Coase (1960), nem os mercados nem a organização interna da firma funcionam a custo zero, e os custos de transação ${ }^{7}$ derivam de assimetrias de informação que dificultam a negociação dos direitos de propriedade. Segundo a Teoria da Nova Economia Institucional (NEI), os custos de transação no mundo real são positivos e são influenciados pelo papel das instituições. As instituições formam o ambiente institucional, composto pelas regras formais e informais e são quem determina a alocação dos direitos de propriedade.

Para o presente trabalho, a importância dos custos de transação decorre do fato de que, quando há externalidades, o preço de um determinado bem não reflete o real custo da sua produção para a sociedade, não há uma eficaz delimitação do direito de propriedade. $\mathrm{Na}$ medida em que esses custos não são refletidos nos preços, levam à não-percepção da escassez do determinado fator de produção - no caso, os recursos naturais - e, por conseqüência, à sua excessiva utilização (NUSDEO, 2006, p. 359). 
A análise de mecanismos utilizados pelo agente econômico para internalizar as externalidades positivas e diminuir custos de transação permite entender a influência do ambiente institucional na prática do agente. E, com isso, podem ser estudadas formas de incentivo a essas condutas privadas a fim de garantir que a proteção ambiental continue a se realizar e, até mesmo, seja incrementada.

\subsection{Internalização pelo agente econômico}

De acordo com Maria Cecília Lustosa (2003, p. 164-165), os fatores institucionais são importantes estímulos para que o agente realize investimentos ambientais e, segundo a autora, são quatro os principais fatores que induzem esse comportamento: a regulamentação estatal; a pressão dos consumidores finais e intermediários; a pressão dos stakeholders, exercida por diversos grupos, desde populações residentes na vizinhança de um empreendimento poluidor até parlamentares e sociedade civil organizada; e a pressão dos investidores.

A empresa procura moldar seu comportamento de acordo com esse ambiente institucional e de maneira a auferir algum benefício. Dessa forma, o meio ambiente tem se tornado uma nova variável introduzida no gerenciamento dos negócios (GIORDANO, 2001, p. 267). O agente responde à pressão pela proteção ecológica, mas ao mesmo tempo faz com que esta lhe agregue valor, ou seja, internaliza as externalidades positivas que produz.

Adota um modelo de gerenciamento denominado gestão ambiental, um conjunto de medidas e procedimentos bem definidos e adequadamente aplicados que visam a reduzir os impactos de um empreendimento sobre o meio ambiente (GIORDANO, 2001, p. 261).

Trata-se, na verdade, de um dever legal, pois a exigência do desenvolvimento da atividade econômica de modo compatível com a defesa do meio ambiente permeia todo o ordenamento jurídico $^{8}$. No entanto, como lembra Clarissa D’Isep (2004, p. 136), não se pode negar o caráter criativo do mercado, que faz de um dever também uma atividade lucrativa, ao utilizar essa postura de proteção ambiental para influenciar a reputação da empresa na sociedade e no mercado. 
Um dos objetivos do agente econômico é a fidelização de clientes ${ }^{9}$. Ela está ligada à questão da qualidade, tomada esta em seu sentido amplo, desde o processo produtivo até o produto em si. As organizações devem se adaptar à demanda que exige especificidades do produto (por exemplo, que o processo produtivo tenha ocorrido atento a certas exigências de proteção ambiental), aprender a lidar com o mercado que passou a exigir cuidados com o meio ambiente.

A fidelização traz o cliente externo para dentro da empresa (BOGMANN, 2002, p. 24), pois a produção passa a ocorrer conforme as determinações dos clientes, para criar o valor desejado por eles - no caso, o valor ambiental - e atender à demanda específica.

Antes que a fidelização ocorra, no entanto, há um custo de transação para identificar os clientes que procuram produtos com aqueles determinados atributos. A fim de diminuir esse custo, o agente pode adotar padrões de referência, que facilitam a coordenação entre as partes, uma vez que reduzem os custos de aquisição da informação sobre o produto e limitam situações sujeitas ao chamado "risco moral" (moral hazard) ${ }^{10}$, criadas pela falta de informação dos compradores e pela possibilidade de que os vendedores dissimulem problemas de qualidade (FARINA, 2003, p. 20).

Como exemplo de padronização pode-se citar a ISO série $14000^{11}$, constituída por uma série de padrões destinados a fornecer às empresas um sistema para gerenciar o impacto ambiental que elas possam causar (GIORDANO, 2001, p. 276).

Entretanto, quando a padronização torna-se insuficiente para atender às necessidades dos agentes e consumidores ou quando passa a ser muito complexa, exigindo certificados que comprovem os padrões estabelecidos, é preciso dar um passo a frente, adotando-se a certificação (NASSAR, 2003, p. 31).

Conforme apresenta Elisabeth Farina (2003, p. 21), quando os compradores não podem verificar por si próprios o atendimento a padrões de qualidade desejada, torna-se necessária a certificação da presença de atributos específicos e desejados dos produtos.

\section{Certificação Ambiental}


A marca de certificação, também chamada de marca de garantia, possui a função de atestar a composição de um produto devido à presença de elementos que ofereçam certo nível de qualidade ou que o produto foi elaborado segundo um determinado procedimento ou método de fabricação (TRENTINI, 2012, p. 81).

Segundo o art. 123 da Lei de Propriedade Industrial (BRASIL, 1996), a marca é usada para distinguir produto ou serviço de outro idêntico, semelhante ou afim, de origem diversa. A marca de certificação, mais especificamente, é usada para atestar a conformidade de um produto ou serviço com determinadas normas ou especificações técnicas, notadamente quanto à qualidade, natureza, material utilizado e metodologia empregada.

Para que ocorra a certificação é necessário um regulamento com determinações claras e objetivas sobre as especificações técnicas das características a certificar, de maneira a possibilitar a adequada supervisão pelo titular da marca (entidade certificadora), bem como medidas de controle e sanções a serem impostas pelo titular em caso de descumprimento (ÂNGULO, 2004).

A certificação serve ao controle de qualidade e de conformidade técnica ao conjunto de especificações precisas que atestem determinado padrão exigido pela entidade certificadora, que pode ser pública ou privada, sem interesse direto no produto atestado. Mas, além da função de garantir certos atributos, a marca de certificação atualmente constitui "parte integrante e estratégica do capital intelectual da empresa" (ÂNGULO, 2004), sendo um diferencial do agente econômico no mercado.

A certificação ambiental é um instrumento de mercado capaz de influenciar a demanda por meio da sinalização e garantia de que um processo produtivo cumpre certos requisitos previamente estabelecidos no que diz respeito à não-agressão ambiental. Com isso, diferencia determinado processo produtivo, certificado, dos demais processos existentes em um dado setor, agregando valor frente a uma demanda qualificada (CARVALHO, L., 2010, p. 24).

\subsection{Certificação ambiental e internalização de externalidades positivas}


A certificação constitui um importante mecanismo para internalizar as externalidades positivas ambientais, uma vez que reconhece as atividades realizadas pelo agente econômico em benefício do meio ambiente e com isso lhe possibilita transacionar com outros agentes que exijam esse tipo de conduta "verde" da outra parte.

Esse instrumento está relacionado à teoria da mercantilização do meio ambiente elaborada por Ronald Coase (1960), denominada também de teoria da extensão do mercado, a qual incorpora a este último o meio ambiente, atribuindo-lhe preços. Os sujeitos privados negociam seus interesses em um sistema de direitos de propriedade, buscando a internalização eficiente das externalidades (DERANI, 2008, p. 92). Delimita-se o direito de propriedade de forma a nele incluir os fatores ambientais, para que possam ser transacionados.

Dessa forma, é possível eliminar por meio da negociação a divergência entre custos privados e custos sociais, que decorre do fato de ao mercado só interessar a transação de bens aos quais corresponda um direito de propriedade definido (ARAGÃO, 1997, p. 37 $38)$.

Logo, para que o bem possa ser incorporado ao mercado é preciso que corresponda a um direito de propriedade bem delimitado, pois ele é que será transacionado. Segundo Yoram Barzel (1997, p. 4), para que os direitos a um ativo sejam completa ou perfeitamente delineados, tanto seu proprietário quanto outros indivíduos potencialmente interessados no ativo devem conhecer plenamente todos seus atributos estimados.

Surge, então, a necessidade de que as externalidades positivas sejam reconhecidas, valoradas e, com isso, incorporadas ao bem, refletindo em seu valor; o que elimina a assimetria de informação e diminui custos de transação. Pois se esse atributo não for bem definido a ponto de poder ser transacionado, o agente deixará de fornecer os benefícios sociais decorrentes da proteção ambiental.

Os preços não refletem adequadamente o valor dos serviços ambientais ${ }^{12}$ prestados, ou seja, o mercado falha na valoração adequada da conservação biológica (NUSDEO, 2008, p. 3-4) e, uma vez que se torne mais vantajoso para o agente produzir sem se preocupar com o meio ambiente, haverá a degradação. 
A certificação ambiental é um instrumento eficiente para estimular a proteção ecológica, pois diminui essa assimetria informacional. A oferta do produto será realizada já com a informação de que ele possui determinados atributos, garantidos pela certificação. Esses benefícios ambientais passarão a fazer parte do direito de propriedade a ser transacionado.

Isso reduz os custos de transação, uma vez que, ao fornecer informação qualificada, facilita a coordenação entre as partes. De tal maneira, aquele produto passará a ser reconhecido e procurado no mercado por conter as características específicas certificadas, será diferenciado de outros produtos não submetidos à certificação. Devido a essa diferenciação e acesso a mercados que valorizam o produto certificado, o agente é estimulado a manter a proteção ambiental praticada.

É difícil determinar se por meio da certificação o agente é diretamente remunerado pelas externalidades positivas que gerou, se há um pagamento direto pelos benefícios. Mas é certo que, mesmo que indiretamente, a empresa ganha com a certificação, pois esta lhe permite atuar em mercados que demandam cada vez mais produtos e serviços cujo processo produtivo tenha ocorrido em observância da proteção ecológica.

Os "selos verdes" da certificação surgem como resposta à falha de mercado representada pela assimetria de informação. Paulo Furquim de Azevedo (2005, p. 122-123) diz que um dos problemas que desta decorrem é a seleção adversa, que "elimina do mercado os produtos de boa qualidade porque o vendedor não consegue convencer o comprador sobre a qualidade do produto".

O vendedor exigirá um alto valor para a transação do bem de alta qualidade e o comprador, ignorante quanto à alta qualidade, aceita pagar somente o valor correspondente à qualidade esperada, que seria inferior. Assim, somente o bem de qualidade inferior - no caso, aquele cujo processo produtivo não esteve atento às condições ambientais - será comercializado e o outro será excluído do mercado, o que não ocorreria se houvesse a certificação a atestar as características do produto.

E, além de atuar como redutora da assimetria informacional, é preciso acrescentar que, uma vez obtido um certo grau de conhecimento e reputação, a marca de certificação fará R. Fac. Dir. UFG, v. 38, n. 2, p. 57-79, jul. / dez. 2014 
com que outros produtores queiram ajustar-se a esses mesmos padrões e dela fazer uso (SENIOR, 2007, p. 488). Consequentemente, a certificação ambiental é um importante instrumento para contribuir com uma significativa melhora da qualidade dos produtos, no tocante à proteção do meio ambiente.

Ademais, a empresa que desenvolve práticas de proteção ambiental a médio e longo prazo pode vir a se tornar mais competitiva no mercado, à medida que essa conduta estimula a inovação e modernização dos processos produtivos, fomentando o uso de tecnologias mais limpas (SENIOR, 2007, p. 486). O que, repita-se, é desejável segundo o ideal de desenvolvimento sustentável.

\section{Incentivos Estatais à Certificação}

Realizadas as ponderações acima, verifica-se que o próprio mercado pode atuar como sinalizador para a adoção de ações ambientais positivas pelos agentes econômicos, a partir de instrumentos como a certificação, uma vez que esta possibilita - e algumas vezes é até mesmo requisito para - o atendimento de demandas específicas.

A empresa responde aos estímulos do mercado porque possui interesses econômicos, já que a própria razão de existência de uma empresa privada é o lucro ${ }^{13}$. No entanto, ao mesmo tempo em que satisfaz interesses privados passa a atender também ao interesse coletivo de um meio ambiente ecologicamente equilibrado.

Em razão disso, e de acordo com o paradigma da sustentabilidade, que busca um desenvolvimento caracterizado por uma relação harmônica entre os aspectos social, econômico e ambiental, propõe-se uma atuação do Estado de modo a orientar a atuação dos agentes, garantindo e otimizando uma prática privada gratificante tanto ao investidor quanto à sociedade (DERANI, 2008, p. 149), como é o caso da certificação. Ele pode impulsionar as empresas à certificação, seja a partir de apoio e incentivos a adotarem certificações privadas ou criando ele mesmo selos próprios.

Nos sistemas de certificação há três atores principais, o Estado, as empresas e as associações. Ao Estado pode competir o papel de executor e coordenador, mas nem sempre, pois a certificação pode ser realizada por instituições privadas, geralmente associações. 
Por outro lado, sempre cabe ao poder público o papel de agente regulamentador ${ }^{14}$. Uma vez que ao Estado cumpre garantir o ambiente institucional, algumas vezes por meio de regulamentações específicas para cada sistema de certificação, outras vezes, regulamentações gerais que servem de balizamento para a certificação (NASSAR, 2003, p. 41-42).

A garantia é dada pelo titular da marca, a entidade certificadora, mas é necessário que as autoridades públicas desempenhem papel de vigilância do cumprimento do regulamento de utilização da marca e das características que ela garante (ÂNGULO, 2004). Cabe a ele auxiliar o setor privado na certificação e monitorar os resultados ao consumidor (NASSAR, 2003, p. 44).

Além da função de regulamentador, há que se considerar o papel do Estado de fomento das condutas privadas desejáveis socialmente. É preciso pensar a forma como o direito age na mudança de perspectiva da apropriação dos recursos naturais para o desenvolvimento econômico (DERANI, 2008, p. 103), para que passe a agir de maneira preventiva, e não só repressiva.

Tendo em vista o panorama da degradação do meio ambiente e estado de alerta em que se encontra a população mundial, é imprescindível que o direito abandone o caráter retardatário diante da questão ambiental e suas incertezas adjacentes, passando a agir segundo os princípios da precaução e da prevenção ${ }^{15}$.

Para isso, é necessário abandonar a postura predominantemente repressiva, pois se pode constatar empiricamente que ela não tem sido plenamente eficaz. O dever do Estado de proteger o meio ambiente engloba também o dever de evitar riscos, adotando uma postura que se antecipe ao dano ambiental (SARLET; FENSTERSEIFER, 2011, p. 183).

Trata-se de repensar a eficiência da construção jurídica acerca da proteção ambiental. É notoriamente sabido que as normas ambientais frequentemente não são cumpridas e, assim, estão longe de garantir a efetiva defesa do meio ambiente. Uma das críticas se funda na crise estrutural da Administração Pública, que não consegue realizar a necessária fiscalização dos instrumentos de comando e controle (relacionados ao poder de polícia do Estado), predominantes no nosso ordenamento. 
Além disso, há diversas razões para explicar por que o direito "chega tarde", tais como: a falta de racionalidade antecipatória; o excesso de cultura vingativa que age a posteriori, em vez de resolver os problemas na raiz; a falta de visão multifacetada sobre a questão ambiental, que é deveras complexa para ser tratada apenas sob o enfoque jurídico; o excesso de exploração parasitária da morosidade processual (FREITAS, 2011, p. 103-104).

Afirma Cristiane Derani (2008, p. 197) que o direito moderno adquire sua legitimação pela eficiência e não pela formalidade de que se reveste. Segundo a autora, para resolver a "crise do direito" é preciso superar os mitos de infalibilidade e perfeição sistêmica formal do ordenamento jurídico diante da realidade, procurando uma adaptação conjuntural eficiente.

Nesse esteio, cabe ao direito se adaptar segundo as conjunturas que se apresentam, dialogando permanentemente com as mudanças sociais (ALTMANN, 2008, p. 23), sempre em busca de dar a efetiva tutela aos interesses coletivos. A complexidade das demandas da sociedade contemporânea, e também os próprios problemas estruturais do Estado, exigem deste estratégias multifacetadas e concatenadas entre si para que se enfrentem desafios como o de frear a degradação do meio ambiente e seus reflexos.

Considerando-se, então, que as instituições de controle estatal falham na proteção ambiental, por motivos como as deficiências relativas à efetiva fiscalização e sanção, para se buscar uma eficiente defesa do meio ambiente é necessária a correção dessas falhas mas, também, contar com mecanismos de incentivo, que induzam práticas mais saudáveis ao meio ambiente. Por isso, cada vez mais se enfatiza a aplicação complementar dos instrumentos de incentivo.

Isso não significa descartar ou diminuir a importância dos instrumentos de comando e controle. Com a inclusão de instrumentos de incentivo positivo o que se pretende é "prevenir a degradação ambiental de tal sorte que não se faça necessária a utilização de instrumentos de comando e controle" (ALTMANN, 2008, p. 24).

É premente uma atitude mais ativa do que passiva, que estimule e sustente condutas benéficas ao meio ambiente. Para isso, o direito ambiental deve ser entendido e R. Fac. Dir. UFG, v. 38, n. 2, p. 57-79, jul. / dez. 2014 
aplicado de acordo com o ideal de desenvolvimento sustentável, exercendo a função de orientar as forças produtivas em uma determinada direção, menos agressiva ao meio ambiente.

Segundo esse paradigma, não há por que se manter estanques a atuação estatal e a atuação do agente econômico em relação ao meio ambiente. Pelo contrário, o que se propõe é que caminhem conjuntamente. Por meio de políticas públicas devem ser estimuladas as ações de proteção ambiental realizadas pelo agente, fazendo com que a atividade econômica se realize de modo compatível à sustentabilidade ambiental.

O Estado não precisa agir somente no sentido de coibir as práticas degradantes. A partir de uma função promocional ele pode também estimular as condutas desejáveis socialmente. Por um lado, isso condiz com o princípio da precaução, pois o incentivo representa um planejamento que busca a não-ocorrência do dano - principalmente por se considerar que a norma proibitiva pode ser descumprida tendo-se em vista os problemas brasileiros de fiscalização e sanção.

Por outro lado, essa atitude promocional e a implementação do princípio da precaução estão diretamente relacionados à realização de outro princípio ambiental, o da cooperação. Este princípio diz respeito a uma atuação conjunta do Estado e sociedade na escolha de prioridades e nos processos decisórios, voltada a objetivos como o de "estabilidade no relacionamento entre liberdade individual e necessidade social" (DERANI, 2008, p. 142; 251), buscando a melhor harmonização entre os valores e as práticas da sociedade, inclusive as da atividade econômica.

Uma das questões mais importantes na economia de bem-estar ${ }^{16}$ é a derivação de uma função de bem-estar social, que agrega preferências individuais em preferências sociais (COOTER; ULEN, 2008, p. 47). A partir dessa ideia é que o Estado deve atuar, intervindo na ordem econômica de maneira a estimular condutas privadas que coadunem com a defesa do meio ambiente, ele deve "convidar" o agente a uma opção de agir convergente com o interesse social (GRAU, 2010, p. 147-148).

Esse tipo de intervenção representa a preocupação estatal com uma eficiência dinâmica do sistema, intervindo no mercado de modo a causar-lhe distorções, alterá-lo, R. Fac. Dir. UFG, v. 38, n. 2, p. 57-79, jul. / dez. 2014 
interferir no seu funcionamento, a fim de fazer com que os resultados produzidos deixem de ser apenas os naturais ou espontâneos, para se aperfeiçoarem às metas ambientais fixadas (NUSDEO, 1993, p. 25-26).

Ao poder público importa a promoção da certificação porque existe o interesse coletivo pelo fato de que colabora para o cumprimento das normas ambientais. Como bem elucida Luiz Carvalho (2010, p. 25), a relação da certificação ambiental com a legislação é auxiliar, uma vez que a regulação da primeira gera o enquadramento da atividade produtiva na segunda, e a supera. Desse modo, a coordenação entre as duas é benéfica; são independentes, mas os objetivos/consequências as unem.

Dentre outros fatores, os critérios fixados para a certificação tomam a legislação ambiental existente como linha base, piso a partir do qual ser partirá. Por isso é importante contar com a presença do Estado no processo, apoiando a criação e consolidação de um sistema de certificação (CARVALHO, L., 2010, p. 81).

Ressalte-se, ainda, que a certificação é um instrumento de grande permeabilidade no mercado, já que o agente facilmente enxerga vantagens econômicas em se certificar, como o acesso a determinados mercados. Por isso, é muito eficiente na alteração de comportamentos do setor produtivo, fazendo com que estes se tornem mais adequados aos objetivos das políticas ambientais.

Em resumo, verifica-se que a certificação ambiental é um mecanismo eficiente para a implementação dos princípios ambientais e por isso deve ser fomentada pelo Estado.

A certificação reconhece as externalidades positivas geradas pela atividade agrária e agrega valor ao produto, o que constitui um atrativo ao agente econômico, que é induzido a manter ou até mesmo maximizar a conduta ambiental que pratica, a qual é desejável socialmente.

Por meio desse mecanismo, precave-se contra um possível dano ambiental, que poderia ocorrer caso o agente não encontrasse motivação em proteger e, ao mesmo tempo, não se sentisse coagido a isso em razão de considerar baixo o risco de sofrer uma sanção devido ao descrédito na fiscalização e eficiência dos processos administrativos e judiciais. 
Além disso, a certificação evidencia o caráter de cooperação entre o poder público e o setor econômico no tocante à proteção ambiental, a qual passa a contar com a participação ativa de vários atores para a tentativa de maior efetividade do direito a um meio ambiente ecologicamente equilibrado, a partir de uma visão de sustentabilidade entre as questões ambientais e econômicas.

Dessa forma, propõe-se a criação de políticas públicas de incentivo e implementação à certificação ambiental da atividade agrária, as quais sejam caracterizadas pelo paradigma do desenvolvimento sustentável.

Para isso, é aconselhável a atuação estatal direta por meio da criação de selos próprios, em que a certificação é coordenada e executada pelo próprio poder público. O que seria de extrema relevância principalmente para a atividade agrária realizada pela agricultura familiar e pequenos produtores, cujo acesso aos grandes sistemas de certificação privados algumas vezes pode ser muito difícil e custoso; o que não exclui a importância da certificação estatal também para sistemas de produção caracterizados pela presença de grandes agentes econômicos.

Outro viés da atuação estatal proposta é o incentivo do Estado para que os agentes que praticam a atividade agrária adotem a certificação realizada por entidades privadas e, junto a isso, o desenvolvimento de regulamentações gerais que sirvam de balizamento para a certificação e também regulamentações específicas para cada sistema de certificação, atentando-se às especificidades dos diferentes sistemas agroindustriais. Pois é necessário que o Estado garanta um ambiente institucional formal propício à implementação da certificação por agentes privados, além de assumir um papel de vigilância do cumprimento do regulamento de utilização da marca, para que a certificação se torne exequível e eficaz ambientalmente.

Essas e outras ações, aliadas aos demais mecanismos de proteção do meio ambiente, como outros instrumentos econômicos e os instrumentos de comando e controle, podem aumentar a eficiência da concretização da proteção ambiental. 
Mas, além dos danos evitados, que causam prejuízos ambientais muitas vezes irreparáveis, políticas públicas que implementem a certificação no país ainda podem produzir vantagens estruturais para o poder público. Uma vez que a óptica adotada é de precaução, evitando-se a ocorrência da degradação ambiental, não serão gerados novos processos administrativos ou judiciais para apuração e punição; ou seja, reduzindo-se o número de novas demandas para a Administração Pública e Poder Judiciário já tão abarrotados.

De tal forma, uma vez implementada com eficientes regulamentações estatais e adotada pelos agentes econômicos, a certificação representará maiores ganhos ambientais, a partir da maior concretização da proteção ambiental; menores custos para o Estado com fiscalização, processamento e punição; e, a partir desses dois fatores, também menores custos sociais.

Ao criar incentivos à certificação, o Estado reconhece os benefícios sociais produzidos a partir de ações privadas e proporciona ao agente econômico condições para que essas externalidades positivas continuem a ser geradas. E, assim, cumpre seu papel de garantidor de um ambiente institucional que promove eficientemente a proteção ambiental.

\section{Conclusão}

A atividade agrária desenvolvida pelo particular gera serviços ambientais que constituem benefícios coletivos, as denominadas externalidades positivas, que revelam o conflito entre interesse privado e interesse social quando não remuneradas.

Por meio da certificação, internalizam-se as externalidades positivas ambientais, que passam a compor o direito de propriedade a ser transacionado. Ela diminui a assimetria de informação, pois sinaliza e garante certos atributos do produto, e, com isso, reduz também os custos de transação, uma vez que ao fornecer informação qualificada facilita a coordenação entre as partes. Assim, a variável ambiental agrega valor ao produto.

A partir da internalização das externalidades positivas e consequente vantagem econômica do agente, este é impulsionado a manter sua conduta benéfica ao meio ambiente. Ou seja, ao mesmo tempo em que a empresa satisfaz seu objetivo de lucro, adota um comportamento adequado ao interesse coletivo. 
Dessa forma, uma vez constatado o caráter indutor do mercado quanto à proteção ambiental, cabe ao Estado a função de intervir no sentido de fomentar as atividades privadas convergentes com o objetivo de um meio ambiente ecologicamente equilibrado.

É papel fundamental do Estado direcionar e promover a concretização da preservação ambiental. Ele deve reconhecer as falhas do ordenamento jurídico, do ineficiente mecanismo de coerção estatal e falhas de mercado (como as externalidades positivas) e agir no sentido de corrigi-las ou propiciar instrumentos para a correção. Para que isso ocorra, devem ser criados incentivos para a adoção e manutenção das condutas socialmente desejadas.

A certificação deve ser incentivada pelo poder público, pois é um instrumento de grande permeabilidade no mercado e, por isso, pode ser muito eficiente para induzir o comportamento do setor produtivo de modo adequado aos objetivos das políticas ambientais. Além de sua importância na implementação dos princípios ambientais, sobretudo os princípios da precaução, da cooperação e do desenvolvimento sustentável.

A promoção da certificação por meio de políticas públicas propiciará o aumento da proteção ambiental de maneira eficiente, antecipando-se aos danos de modo a evitá-los; fomentando uma conduta interessante ao agente e benéfica ao meio ambiente e à sociedade, de modo a promover a prática de uma atividade agrária que se coaduna com o ideal de um desenvolvimento sustentável.

\section{Referências}

ALTMANN, Alexandre. A função promocional do direito e o pagamento pelos serviços ecológicos. Revista de Direito Ambiental, São Paulo, ano 13, n. 52, p. 11-26, out./ dez. 2008.

ÂNGULO, Astrid Coromoto Uzcategui. A marca de certificação e suas particularidades.

Revista da Associação Brasileira da Propriedade Industrial, Rio de Janeiro, n. 68, p. 3-10, jan./ fev. 2004. Disponível em:

<http://www.cjp.ula.ve/gpi/documentos/marcas_certificacion.pdf>. Acesso em: 15 abr. 2012. 
ANTUNES, Paulo de Bessa. Direito ambiental. 12. ed. rev. e atual. Rio de Janeiro: Lumen Juris, 2010.

ARAGÃO, Maria Alexandra de Sousa. O princípio do poluidor pagador: pedra angular da política comunitária do ambiente. Coimbra: Coimbra Editora, 1997.

AZEVEDO, Paulo Furquim de. Economia dos contratos. In: ZYLBERSZTAJN, Decio; SZTAJN, Rachel (Org.). Direito \& Economia: análise econômica do direito e das organizações. Rio de Janeiro: Elsevier, 2005. p. 102-136.

BARZEL, Yoram. Economic analysis of property rights. New York: Cambrige University Press, 1997.

BOGMANN, Itzhak Meir. Marketing de relacionamento: estratégias de fidelização e suas implicações financeiras. São Paulo: Nobel, 2002.

BRASIL. Constituição da República Federativa do Brasil, de 5 de outubro de 1988.

Disponível em: <http://www.planalto.gov.br/ccivil_03/constituicao/constituiçao.htm>. Acesso em: 20 ago. 2011.

Lei no 9.279, de 14 de maio de 1996. Disponível em:

<http://www.planalto.gov.br/ccivil_03/leis/L9279.htm>. Acesso em 24 mar. 2012.

CARVALHO, Edson Ferreira de. Meio ambiente e direitos humanos. Curitiba: Juruá, 2010.

CARVALHO, Luiz Souza Lima da Silva. Desenvolvimento responsável: abordagens e implicações da certificação ambiental do setor sucroalcooleiro brasileiro. Dissertação (Mestrado em Direito) - Universidade de São Paulo, São Paulo, 2010.

COASE, Ronald H. The problem of social cost. Journal of Law and Economics, v. 3, p.120, oct. 1960. Disponível em:

<http://weber.ucsd.edu/ jlbroz/Courses/POLI200C/syllabus/Coase_social\%20cost.pdf >. Acesso em: 17 maio 2011.

COOTER, Robert; ULEN, Thomas. Law \& Economics. 5th ed. Boston: Addison-Wesley, 2008.

D'ISEP, Clarissa Ferreira Machado. Direito ambiental econômico e a ISO 14000. São Paulo: Editora Revista dos Tribunais, 2004.

DALY, Herman; FARLEY, Joshua. Ecological economics: principles and applications. Washington, DC: Island Press, 2004.

DERANI, Cristiane. Direito ambiental econômico. 3. ed. São Paulo: Saraiva, 2008.

FARINA, Elisabeth M. M. Q. Padronização em sistemas agroindustriais. In: ZYLBERSZTAJN, Decio; SCARE, Roberto Fava (Org.). Gestão de qualidade no agribusiness: estudos e casos. São Paulo: Atlas, 2003. p. 18-29.

FREITAS, Juarez. Sustentabilidade: direito ao futuro. Belo Horizonte: Editora Fórum, 2011. 
GIORDANO, Samuel Ribeiro. Gestão ambiental no sistema agroindustrial. In: ZYLBERSZTAJN, Decio; NEVES, Marcos Fava (Org.). Economia e gestão dos negócios agroalimentares: indústria de alimentos, indústria de insumos, produção agropecuária, distribuição. São Paulo: Pioneira, 2001. p. 255-281.

GRAU, Eros Roberto. A ordem econômica na Constituição de 1988: interpretação e crítica. 14. ed. São Paulo: Malheiros, 2010.

LEITE, José Rubens Morato; PILATI, Luciana Cardoso; JAMUNDÁ, Woldemar. Estado de direito ambiental no Brasil. In: KISHI, Sandra A. S.; SILVA, Solange T. da; SOARES, Inês V. P. (Org.). Desafios do direito ambiental no século XXI: estudos em homenagem a Paulo Affonso Leme Machado. São Paulo: Malheiros, 2005. p. 611-634.

LUSTOSA, Maria Cecília Junqueira. Industrialização, meio ambiente, inovação e competitividade. In: MAY, Peter Hermann; LUSTOSA, Maria Cecília; VINHA, Valéria da (Org.). Economia do meio ambiente: teoria e prática. Rio de Janeiro: Elsevier, 2003. p. 155172.

NASSAR, André Meloni. Certificação no agribusiness. In: ZYLBERSZTAJN, Decio; SCARE, Roberto Fava (Org.). Gestão de qualidade no agribusiness: estudos e casos. São Paulo: Atlas, 2003. p. 30-46.

NUSDEO, Ana Maria de Oliveira. O papel dos mercados e dos direitos de propriedade na proteção ambiental, 2008. Disponível em:

<http://www.law.yale.edu/documents/pdf/sela/Nusdeo_Portuguese.pdf>. Acesso em: 14 jan. 2012.

O uso de instrumentos econômicos nas normas de proteção ambiental. Revista da Faculdade de Direito da Universidade de São Paulo, São Paulo, v. 101, p. 357-378, jan./ dez. 2006.

NUSDEO, Fábio. Fundamentos para uma codificação do Direito Econômico. Tese (Concurso de provimento do cargo de Professor Titular) - Faculdade de Direito da Universidade de São Paulo, São Paulo, 1993.

RODRIGUES, Marcelo Abelha. O direito ambiental no século 21. Revista de Direito Ambiental, São Paulo, ano 13, n. 52, p. 125-137, out./ dez. 2008.

SARLET, Ingo Wolfgang; FENSTERSEIFER, Tiago. Direito constitucional ambiental: estudos sobre a constituição, os direitos fundamentais e a proteção do ambiente. São Paulo: Editora Revista dos Tribunais, 2011.

SENIOR, Alexa et al. Responsabilidad ambiental: factor creador de valor agregado en las organizaciones. Revista de Ciencias Sociales, Maracaibo, n. 3, v. 13, p. 484-494, dic. 2007. Disponível em: <http://www.scielo.org.ve/pdf/rcs/v13n3/art09.pdf>. Acesso em: 13 mar. 2012. 
SZTAJN, Rachel. Ensaio sobre a natureza da empresa: organização contemporânea da atividade. Tese (Concurso de provimento do cargo de Professor Titular) - Faculdade de Direito da Universidade de São Paulo, São Paulo, 2001.

Externalidades e custos de transação: a redistribuição de direitos no novo código civil. Revista de Direito Mercantil, Industrial, Econômico e Financeiro, São Paulo, ano XLIII, n. 133, p. 7-31, jan./ mar. 2004.

TRENNEPOHL, Terence Dornelles. Incentivos fiscais no direito ambiental. São Paulo: Saraiva, 2008.

TRENTINI, Flavia. Teoria geral do direito agrário contemporâneo. São Paulo: Atlas, 2012.

WATANABE, Kassia; SCHMIDT, Carla Maria. A multifuncionalidade da agricultura e suas externalidades positivas para o desenvolvimento local. In: XLVI CONGRESSO DA SOCIEDADE BRASILEIRA DE ECONOMIA, ADMINISTRAÇÃO E SOCIOLOGIA RURAL, 2008, Rio Branco. Anais eletrônicos. Disponível em: <http://www.sober.org.br/palestra/9/930.pdf>. Acesso em: 20 mar. 2011.

${ }^{1}$ Não se olvida que a natureza possui um valor intrínseco, chamado de valor de existência, decorrente do simples fato de ela existir, de subsistir em suas características inerentes, independentemente de qualquer utilidade que possa proporcionar. No entanto, não se pode dissociá-la completamente do aspecto humano, uma vez que a própria existência do homem está a ela vinculada.

${ }^{2}$ Como enfatiza Juarez Freitas (2011, p. 15; 40-41; 50), o desenvolvimento aparece de modo expresso na Constituição, mas a sustentabilidade desponta como um princípio constitucional-síntese a guiá-lo, porque o único desenvolvimento que interessa é aquele que se constitui mutuamente com a sustentabilidade. Sustentabilidade, segundo o autor, vai além do conceito atualmente limitado de ser a capacidade da geração presente de suprir suas necessidades sem afetar a possibilidade das gerações futuras de suprir as suas. Para o autor, "trata-se do princípio constitucional que determina, independentemente de regulamentação legal, com eficácia direta e imediata, a responsabilidade do Estado e da sociedade pela concretização solidária do desenvolvimento material e imaterial, socialmente inclusivo, durável e equânime, ambientalmente limpo, inovador, ético e eficiente, no intuito de assegurar, preferencialmente de modo preventivo e precavido, no presente e no futuro, o direito ao bem-estar físico, psíquico e espiritual, em consonância homeostática com o bem de todos", entendida a homeostase como a capacidade biológica e institucional de promover o reequilíbrio dinâmico.

3 "O princípio da defesa do meio ambiente conforma a ordem econômica (mundo do ser), informando substancialmente os princípios da garantia do desenvolvimento e do pleno emprego. Além de objetivo, em si, é instrumento necessário - e indispensável - à realização do fim dessa ordem, o de assegurar a todos existência digna. Nutre também, ademais, os ditames da justiça social. Todos têm direito ao meio ambiente ecologicamente equilibrado, bem de uso comum do povo - diz o art. 225, caput" (GRAU, 2010, p. 256).

${ }^{4}$ Acrescentam Ingo Sarlet e Tiago Fensterseifer (2011, p. 154): "Afinal de contas, todos somos reféns dos danos ambientais decorrentes das mudanças climáticas, assim como todos somos, em maior ou menor medida, responsáveis pela reversão de tal problema ambiental".

${ }^{5}$ Nesse sentido: "os serviços do ecossistema têm algumas características que o tornam extremamente importantes economicamente. Provavelmente a maior importância é que é pouco provável que possamos desenvolver substitutos para a maioria desses serviços, incluindo a capacidade de proporcionar o habitat adequado para os seres humanos. Nós pouco entendemos como esses serviços são gerados, e não temos conhecimento de todos eles" (tradução nossa) (DALY; FARLEY, 2004, p. 106).

${ }^{6}$ Nesse sentido, Maria Aragão (1997, p. 33) explica: “A denominação efeitos externos ao mercado é compreensível, porque se trata de transferência de bens ou prestações de serviços fora dos mecanismos do mercado. São transferências por meios não económicos na medida em que não lhes corresponde qualquer fluxo contrário de dinheiro. Sendo transferências 'a preço zero', o preço final dos produtos não as reflecte, e por isso não pesam nas decisões de produção ou consumo, apesar de representarem verdadeiros custos ou benefícios sociais decorrentes da utilização privada dos recursos comuns".

${ }^{7}$ Rachel Sztajn (2004, p. 9) define: "Transação, no jargão dos economistas, é qualquer operação econômica, operação de circulação de riqueza entre agentes econômicos. Custos de transação são aqueles custos em que se incorre que, de alguma forma, oneram a operação, mesmo quando não representados por dispêndios financeiros feitos pelos agentes, mas que decorrem do conjunto de medidas tomadas para realizar uma transação".

Em uma análise mais detalhada: "Os custos de transação são os custos de troca. Uma troca tem três etapas. Primeiro, um parceiro de troca tem de ser localizado. Trata-se de encontrar alguém que queira comprar o que você está vendendo ou vender o que você está comprando. Em segundo lugar, uma barganha deve ser atingida entre os parceiros de troca. uma barganha é alcançada por meio de negociação bem sucedida, que inclui a elaboração de um acordo. Em terceiro lugar, depois que uma barganha tiver sido alcançada, deve ser aplicada. Aplicação envolve monitorar o 
desempenho das partes e punir violações do acordo. Podemos chamar as três formas de custos de transação correspondentes a esses três passos de uma troca: (1) custos de pesquisa [search costs], (2) custos de negociação [bargaining costs], e (3) custos de aplicação [enforcement costs]" (tradução nossa) (COOTER; ULEN, 2008, p. 91-92).

${ }^{8}$ Podem ser citados os principais dispositivos que assim dispõe: art. 225 e art.170, incisos III e VI da Constituição Federal; art. $2^{\circ}$ da Política Nacional do Meio Ambiente (Lei n. 6.938/81) e art.51, XIV, do Código de Defesa do Consumidor.

9 "No contexto empresarial, cliente fiel é aquele que está envolvido, presente; aquele que não muda de fornecedor, e mantém consumo freqüente, optando por uma organização em particular, sempre que necessita de um determinado produto ou similar" (BOGMANN, 2002, p. 21).

10 "Denomina-se risco moral ou moral hazard a possibilidade de ação oportunista de uma das partes da transação que detém informação privilegiada sobre o bem ou serviço transacionado, e tira proveito em detrimento de sua contraparte" (FARINA, 2003, p. 20).

${ }^{11}$ Norma editada pela International Organization for Standardization, que possui 110 países associados, com sede em Genebra na Suíça. No Brasil, ela é representada pela Associação Brasileira de Normas Técnicas (ABNT).

12 Dentre as práticas de produção agrícola consideradas adequadas à produção sustentável, podem-se citar: conservação do solo e água, conservação da biodiversidade (manutenção de áreas florestais nativas, conservação e replantio de espécies vegetais nativas, manutenção das áreas de preservação permanentes, proibição e fiscalização rigorosa do corte de matas nativas), utilização de práticas agronômicas saudáveis, reciclagem de matérias-primas rurais, educação ambiental, dentre diversas outras (GIORDANO, 2001, p. 265-266).

${ }^{13}$ Nesse sentido, Clarissa D’Isep (2004, p. 43) afirma que “(...) uma gestão empresarial que se preze, isto é, que faça jus às características econômicas, vai se adequar à legislação ambiental e, se possível, dela extrair a lucratividade, que, numa versão capitalista, será 'socializando os custos e privatizando o lucro'. Não se pretende dizer que a empresa não deva obter lucro e se tornar social, mesmo porque, ao obtê-lo, ela já exerce um papel social, pois garante a sua sobrevivência (e, conseqüentemente, garante empregos, hoje o maior desafio do sistema capitalista). Tampouco pretendemos externar que ela deva socializar os prejuízos. Apenas descrevemos as suas características".

14 "O direito é sistema aberto e, como é influenciado pelo meio que o produz não pode ignorar que, quando agentes econômicos atuam, criando para si novas formas de relacionamento, elas devem ser captadas pelo ordenamento que disporá quanto à eficácia dos efeitos" (SZTAJN, 2001, p. 9).

15 "O princípio da prevenção é aquele em que se constata, previamente, a dificuldade ou a impossibilidade de reparação ambiental, ou seja, consumado o dano ambiental, sua reparação é sempre incerta ou excessivamente onerosa. Doutra banda, o princípio da precaução [...] aplica-se àqueles casos em que o perigo é abstrato, de um estado de perigo em potencial [...] Dessa forma, o princípio da precaução consiste em evitar que medidas de proteção sejam adiadas em razão da incerteza que circunda os eventuais danos ambientais" (TRENNEPOHL, 2008, p. 51). Em resumo, segundo Marcelo Abelha Rodrigues (2008, p. 134): "Previne-se contra o dano que se conhece. Precave-se contra o risco desconhecido".

${ }^{16}$ Claramente optada pela Constituição Federal de 1988, que traz como um dos objetivos fundamentais da República a promoção do bem-estar social (BRASIL, 1988, art. $3^{\circ}$, IV) e, mais a frente, declara que a ordem econômica tem por fim assegurar a todos existência digna, conforme os ditames da justiça social (BRASIL, 1988, art. 170). 